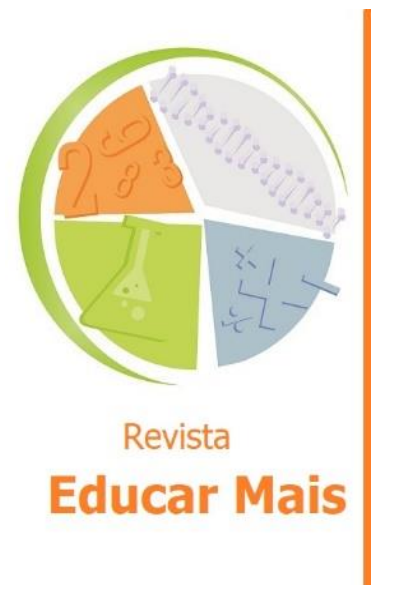

\section{Contribuições do pensamento de Georgescu-Roegen e Hans Jonas para a Educação em Ciências e Tecnologia}

\author{
Georgescu-Roegen and Hans Jonas' thoughts contributions to Science \\ and Technology Education
}

\section{Contribuciones del pensamiento de Georgescu-Roegen y Hans Jonas a la Educación Científica y Tecnológica}

Iara Maitê Campestrini Binder ${ }^{1}$; Ana Paula Grimes de Souza ${ }^{2}$

\title{
RESUMO
}

A maneira de agir dos seres humanos no mundo tem provocado mudanças na natureza e no comportamento social a tal ponto, que o ideal de um desenvolvimento sustentável torna-se insustentável. Para sensibilizar um olhar sistêmico e reflexivo sobre a condição humana, o ser e estar neste planeta que é finito, este estudo objetiva problematizar uma relação possível entre o princípio responsabilidade de Hans Jonas, as reflexões econômica-entrópica de Georgescu-Roegen e a Educação em Ciências e Tecnologia (ECT). Subsidia este estudo, um ensaio teórico que fornece as bases informativas para fazer com que as Ciências da Natureza, a Economia e a Filosofia se encontrem dialogicamente com vistas à conscientização e à preservação das diferentes formas de vida, da natureza e da própria humanidade. Tais reflexões voltam-se à ECT, fomentando a interdisciplinaridade e a visão holística tanto na formação de professores quanto nas áreas técnicas e tecnológicas, das ciências da natureza e humanas

Palavras-chave: Leis da termodinâmica; Princípio responsabilidade; Educação em Ciências e Tecnologia; CTS.

\begin{abstract}
Mankind behavior has caused changes in nature and social behavior to such an extent that the ideal of sustainable development has become unsustainable. In order to sensitize a systemic and reflective look at the human condition as well as at the state of being on this finite planet, this study aims at problematizing a possible relationship between the responsibility principle developed by Hans Jonas, the economic-entropic reflections depicted by Georgescu-Roegen and Education in Science and Technology (ECT). A theoretical essay that provides the informative bases to make the Sciences of Nature, Economics and Philosophy meet dialogically with a view to raising awareness and preserving the different forms of life, of nature and of humanity itself scaffolds this study. These reflections turn to ECT, fostering interdisciplinarity and a holistic view both in teacher education and in the technical and technological areas of natural and human sciences.
\end{abstract}

Keywords: Laws of thermodynamics; Principle of responsibility; Science and Technology Education; STS.

\section{RESUMEN}

La forma de actuar del ser humano en el mundo ha provocado cambios en la naturaleza y en el comportamiento social hasta tal punto que el ideal de desarrollo sostenible se vuelve insostenible. Para sensibilizar una mirada sistémica y reflexiva sobre la condición humana, el ser y estar en este planeta que es finito, este estudio

\footnotetext{
${ }^{1}$ Doutoranda em Educação Científica e Tecnológica na Universidade Federal de Santa Catarina (UFSC) e Professora do Instituto Federal de Santa Catarina, Jaraguá do Sul/SC - Brasil. E-mail: iara.campestrini@ifsc.edu.br

${ }^{2}$ Doutoranda em Educação Científica e Tecnológica na Universidade Federal de Santa Catarina (UFSC) e Professora Grupo Ânima Digital, Joinville/SC - Brasil. E-mail: anapaulagrimes@gmail.com
} 
pretende problematizar una posible relación entre el principio de responsabilidad de Hans Jonas, las reflexiones económico-entrópicas de Georgescu-Roegen y la Educación en Ciencia y Tecnología (ECT). Este estudio se apoya en un ensayo teórico que proporciona las bases informativas para hacer confluir dialógicamente las Ciencias de la Naturaleza, la Economía y la Filosofía, con el fin de concienciar y preservar las diferentes formas de vida, la naturaleza y la propia humanidad. Dichas reflexiones se dirigen a la ECT, fomentando la interdisciplinariedad y la visión holística tanto en la formación del profesorado como en las áreas técnicas y tecnológicas de las ciencias naturales y las humanidades.

Palabras clave: Leyes de la termodinámica; Principio responsabilidad; Enseñanza de la Ciencia y la Tecnología; CTS.

\section{INTRODUÇÃO}

Em vinte anos, a quantidade de plásticos nos oceanos será o triplo da atual, chegando a 29 milhões de toneladas, informa uma reportagem ${ }^{3}$. Outras pesquisas apontam para um aumento da temperatura média do planeta de até $3,2^{\circ} \mathrm{C}$ até o ano de $2030^{4}$. Um mar de plásticos e o aquecimento global! Esses dois temas, constantemente pesquisados e retratados nos diferentes meios de comunicação, ilustram o quanto a ação do homem, na relação de dominação da natureza e transformação do meio ambiente, o está tornando escravo da sua própria criação. Numa lógica linear de uso dos recursos naturais em prol de um progresso e desenvolvimento científico e tecnológico, as consequências ecológicas e ambientais são postas como longínquas em espaço e tempo. No entanto, elas estão à nossa porta. Aumento do nível do mar, ondas de calor em períodos menores de tempo, aumento de ciclones com intensidade maior, possibilidade de desaparecimento de espécies animais e plantas, são processos que afetam toda a biosfera terrestre, da qual somos parte.

Ao refletir sobre a finitude do planeta Terra e sobre a influência da ação do ser humano nesta única casa que a humanidade possui para viver, os estudos de Nicholas Georgescu-Roegen (G-R) e Hans Jonas nos estimulam para esta compreensão, principalmente ao adentrar o campo educacional, de onde tensiona-se para um olhar sistêmico e complexo do qual o ensino de ciências não deve esquivarse. Indaga-se, portanto, que elementos das leis da Ciências da Natureza e das reflexões econômicaentrópicas de G-R dialogam com o princípio da responsabilidade de Hans Jonas com vistas à ECT para uma vida ambientalmente mais sustentável?

O presente estudo tem como finalidade provocar reflexões para uma ECT que abarque novos olhares, para além dos conceituais e puramente técnicos, onde o encontro das Ciências da Natureza, da Economia e da Filosofia seja o propulsor de diálogos interdisciplinares na promoção de uma vida ambientalmente sustentável. Para tal, tem-se como objetivos: compreender como as leis das Ciências da Natureza fundamentam a reflexão econômica-entrópica de G-R; compreender aspectos da teoria da responsabilidade proposta por Hans Jonas que possam dialogar com as reflexões de G-R; e enfatizar que este estudo encontra na ECT campo fértil para a construção do conhecimento pertinente.

As seções que apresentam este estudo iniciam com apresentação das reflexões de G-R, sobre a relação das leis da termodinâmica e o limiar do desenvolvimento econômico e industrial, na Seção 2.

\footnotetext{
${ }^{3}$ Disponível em: <https://www.nationalgeographicbrasil.com/meio-ambiente/2020/07/em-2040-lixo-plasticonos-oceanos-podera-ser-o-triplo-do-atual> Acesso em 10..dez.2020

${ }^{4}$ Disponível em: <https://g1.globo.com/natureza/noticia/2019/11/26/entenda-os-impactos-do-aquecimentoglobal-se-a-temperatura-subir-ate-15c-ou-mais-de-2c.ghtml> Acesso em $1^{\circ} .$. dez.2020.
} 
Com o alerta sobre a degradação dos recursos de energia e matéria, os efeitos nocivos da cumulativa poluição e a interferência das atividades econômicas de uma geração nas das futuras gerações, G-R aproxima-se dos pensamentos do filósofo Hans Jonas. Diante dos riscos gerados pela intervenção humana sobre a natureza, doravante inimagináveis, que ultrapassam o espaço e o tempo desta geração, $\mathrm{H}$. Jonas considera uma nova ética para a civilização tecnológica, uma responsabilidade que o ser humano deve assumir. Aspectos desta nova ética são apresentados na seção 3.

A seção 4 evidencia a importância das reflexões de G-R e de $H$. Jonas para o campo educacional. Em especial, para a ECT, voltada tanto para a formação de professores quanto para a formação de engenheiros, técnicos, economistas, e profissionais de outras áreas que possam vir a atuar também como professores. Neste momento, são importantes as reflexões de Edgar Morin sobre a construção do conhecimento pertinente e que encontram aporte nas preocupações dos autores acima citados. Na seção 5, algumas considerações são apresentadas.

\section{GEORGESCU-ROEGEN: DEGRADAÇÃO ECONÔMICA-ENTRÓPICA E O MUNDO FINITO}

Os estudos de G-R, matemático e estatístico de formação, fazem emergir um novo olhar para os fundamentos das ciências naturais ao relacioná-los com o desenvolvimento econômico e industrial. Mais especificamente, G-R tratou da física termodinâmica, destacando-a como a única, dentre as ciências físicas e químicas, em que a vida tem importância. G-R faz um alerta sobre as consequências do desenvolvimento industrial e econômico que são pautadas nas leis da Termodinâmica, sugerindo uma alteração radical na forma clássica de entender este desenvolvimento, considerando o funcionamento da Biosfera, numa perspectiva em que a economia humana se insere no sistema Terra.

Segundo G-R, no processo econômico, o que entra consiste em recursos naturais de valor e o que é rejeitado, em resíduos sem valor. Da perspectiva da termodinâmica, qualitativamente, "a matériaenergia absorvida pelo processo econômico o é num estado de baixa entropia e sai num estado de alta entropia" (G-R, 2012, p.57). Ou seja, os recursos naturais de valor podem ser relacionados com a matéria-energia de baixa entropia. Os resíduos sem valor, por sua vez, relacionam-se à matériaenergia de alta entropia. Mais adiante se elucidará o conceito de matéria-energia, haja vista que a Termodinâmica Clássica trata de energia e não de matéria.

G-R esclarece que, qualitativamente, a energia se apresenta em dois estados: a energia utilizável ou livre e a energia não utilizável ou presa. A primeira, livre, implica certa estrutura organizada; a segunda, não utilizável pelo homem, implica uma energia caoticamente dissipada, em desordem. De acordo com a Lei da Entropia, ou Segunda Lei da Termodinâmica, a entropia de um sistema fechado aumenta constantemente, ou seja, a ordem desse sistema se transforma continuamente em desordem. (G-R, 2012)

A energia livre ou utilizáve/à qual o homem pode ter acesso é proveniente de duas fontes: uma é o estoque de energia livre dos depósitos minerais da Terra; a outra, é um fluxo de raios solares interceptados pela Terra. Desse fluxo de energia, fonte primeira de vida na Terra, o homem não é possuidor, uma vez que o fluxo de energia solar atualmente utilizado não compromete o uso por gerações futuras. Por outro lado, é do estoque dos minerais terrestres (matéria) que são obtidos os recursos de baixa entropia usados na fabricação dos bens e como fontes de energia e é "a utilização 
econômica do estoque terrestre de baixa entropia [que] constitui o principal problema para o destino da espécie humana" (G-R, 2012, p. 68).

G-R analisa que todos os organismos vivos vivem de baixa entropia encontrados imediatamente no ambiente, com exceção do homem, que cozinha a maior parte dos alimentos e transforma os recursos naturais na produção tanto de trabalho mecânico quanto em diferentes objetos de utilidade. Isto faz parte da atividade econômica do homem: cada objeto tem valor econômico e está submetido a um aumento entrópico que não pode ser ignorado. (G-R, 2012)

Com isso, G-R considera que a lei da Entropia aplica-se não somente à energia, que é dissipada irreversivelmente na forma de calor, mas também à matéria, onde há um desgaste natural devido seu uso e, enquanto resíduo, pode não vir a ser reciclável, e se for, será ao custo de uso de mais energia. Desta análise, o estudioso formulou o que denominou de quarta lei da termodinâmica: "Em todo sistema fechado, a matéria utilizável se degrada irreversivelmente em matéria não utilizável" (G-R, 2012, p. 169). Reforçando sua tese da degradação irreversível da matéria, G-R (2012) sintetiza que nenhum trabalho pode ser obtido sem a utilização de matéria, sem degradar em matéria não utilizável alguma matéria utilizável, e nenhuma substância pode ser purificada.

Dois pontos podem ser destacados na tese de G-R. O primeiro, é a análise do processo entrópico voltado à matéria, para além da visão clássica da entropia que envolve a energia. O segundo ponto é a utilização do estoque de matéria da Terra, tanto em termos de energia quanto em termos de matéria. Assim, por um lado tem-se uma sustentabilidade ambiental que não é alcançável, pela própria natureza entrópica do nosso planeta, e por outro lado, este processo sendo agravado pelo uso exacerbado do estoque de energia-matéria livre que compõem os recursos naturais de valor.

G-R não nega as contribuições do progresso das ciências e da engenharia, no entanto, afirma que "nenhuma tecnologia conseguirá eliminar totalmente os aspectos entrópicos da extração, da transformação e da utilização das matérias-primas necessárias ao modo de produção industrial" (G$\mathrm{R}, 2012$, p.42). Além disso, a humanidade não deixará de usufruir dos confortos advindos da evolução tecnológica e científica, pela sua dependência aos instrumentos exossomáticos. Por outro lado, G-R (2012) considera a reeducação da população para utilização dos bens que ainda podem ser usados ou reparados, aumentando sua vida útil e conduzindo as indústrias a investirem na produção de bens duráveis, além da conscientização das pessoas da 'sede mórbida das engenhocas extravagantes' e desnecessárias. Tais pontos compõem o programa bioeconômico mínimo, proposto por G-R. Pelos limites desta apresentação, tal programa poderá ser abordado em detalhes em futuros estudos.

No entanto, a reeducação e a conscientização fazem emergir a necessidade do ser humano e da sociedade pensar diferente sua relação com os bens que consomem, com a natureza e com a sociedade. Apesar da degradação da matéria e energia ser irreversível, a ação em prol da fabricação de produtos 'maiores e melhores' endossa esta degradação. Esse pensar diferente requer, para além de reconhecer a natureza entrópica do processo econômico, uma nova ética diante da Biosfera do planeta Terra. Para ampliar nossa reflexão, a próxima seção abordará o princípio da responsabilidade de Hans Jonas.

\section{HANS JONAS: PRINCÍPIO RESPONSABILIDADE E O ESTAR NO MUNDO}

Nascido na Alemanha, de origem judaica, filósofo com profunda formação humanística, Hans Jonas nos convida a refletir sobre uma nova ética diante dos efeitos do desenvolvimento científico e 
tecnológico. Segundo o filósofo, essa nova ética vai além dos limites do ser humano, tratados pela ética tradicional no aqui e agora, e envolve um conscientizar-se da continuidade da existência da humanidade, das futuras gerações.

Como indicou G-R, o homem utiliza do desenvolvimento científico e tecnológico para promover a evolução de instrumentos exossomáticos, instrumentos produzidos pelo homem, os quais não pertencem ao seu corpo, mas que aumentam sua eficiência, velocidade e capacidade de realização de tarefas. Hans Jonas endossa que este desenvolvimento, influenciadoras da evolução exossomática, era outrora visto como uma necessidade. Agora, "na forma da moderna técnica, a techne transformou-se em um infinito impulso da espécie para adiante, seu empreendimento mais significativo" (JONAS, 2006, p.43).

Para H. Jonas, "a conquista de um domínio total sobre as coisas e sobre o próprio homem surgiria como uma realização do seu destino" (2006, p.43). Coloca-se implícito a tal domínio, a cegueira em relação às benesses da tecnologia, em que o ônus (poluição, resíduos, uso dos estoques de energia e matéria) é confiado numa solução advinda da ciência e cuja causa advém do não reconhecimento da natureza entrópica do processo econômico.

Por ocupar um lugar central nos fins da vida humana, a tecnologia deve assumir um significado ético. Essa nova ética "tem a ver com ações que tem uma projeção causal sem precedentes na direção do futuro, acompanhadas por uma consciência prévia que, mesmo incompleta, vai muito além daquela outrora existente. Ajunte-se a isso a magnitude bruta dos impactos de longo prazo e também, com frequência, a sua irreversibilidade." (JONAS, 2006, p. 22).

O princípio responsabilidade de Hans Jonas apresenta-se da forma: "Age de tal maneira que os efeitos de tua ação sejam compatíveis com a permanência de uma vida humana autêntica, [ou ainda] não ponhas em perigo a continuidade indefinida da humanidade na Terra" (JONAS, 2006, p. 18). Esse imperativo vem ao encontro das reflexões de G-R ao pontuar a necessária conscientização da vulnerabilidade da natureza frente à intervenção tecnológica do homem, cujo crescimento exagerado coloca em jogo a existência da própria humanidade.

Conforme estudos de Battestin e Ghiggi (2010), o princípio responsabilidade fundamenta-se pela 'heurística do medo'. Explica-se. O medo torna-se propulsor de uma ação responsável, parte do reconhecimento das limitações do saber científico e das consequências incertas do progresso tecnológico e mobiliza, "é do medo fundado que deriva a atitude ética fundamental, repensada a partir da vontade de evitar o pior" (Ibidem, p.76).

O Bem, o Dever e o Ser caracterizam outra categoria do princípio responsabilidade. O Bem é entendido como pertencente ao Ser e pode originar um Dever na medida em que existe uma vontade de transformar este Bem em uma ação. H. Jonas defende que "se somos responsáveis pelo Ser, somos responsáveis pelo futuro que ainda não existe, mas que está projetado pela continuidade do direito de ser e estar no mundo" (BATTESTIN; GHIGGI, 2010, p. 80). Assim como, "ser responsável efetivamente por alguém ou por qualquer coisa em certas circunstâncias (mesmo que não assuma e nem reconheça tal responsabilidade) é [...] inseparável da existência do homem" (JONAS, 2006, p. 176). Nesse contexto, a Responsabilidade Paterna e a Responsabilidade Política são apresentadas como outra categoria fundante da nova ética. Mesmo com características diferentes, assemelham-se por não poder ser interrompidas nem deixar de existir, pois tomam decisões em relação à vida, pela e na sua continuidade no presente e no futuro (BATTESTIN; GHIGGI, 2010). 
Sendo inerentes ao Ser humano, capazes de fazer emergir uma ação consciente de cuidado e zelo pelo outro (homens, animais, vegetais), a Responsabilidade e o Bem também são invocados para agir de um modo diferente nesta civilização cada vez mais tecnológica e, por consequência, consumidora de mais recursos materiais e de energia. Neste estudo, G-R e $\mathrm{H}$. Jonas provocam para esta ação consciente na medida em que a tomada de consciência exige a escuta, o colocar-se no lugar do outro, o instinto de sobrevivência e o temor pelo que pode vir a acontecer caso ações não sejam tomadas, seja no plano individual, seja no plano coletivo e de políticas públicas. Acreditamos que tais reflexões não podem ser eximidas do espaço que possibilita tais encontros: o espaço educacional. princípio da responsabilidade de Hans Jonas.

\section{EDUCAÇÃO EM CIÊNCIAS E TECNOLOGIA: ESPAÇO DE ENCONTROS E DISCUSSÕES}

O princípio da responsabilidade e o reconhecimento da natureza entrópica do processo econômico encontram-se imbricados no sujeito que toma consciência do imperativo tecno-lógico, cujo objetivo é justamente eliminar este sujeito, sua consciência e sua liberdade. $\mathrm{H}$. Jonas faz crítica à hiperespecialização das ciências que mutila e desloca a noção própria de ser humano. A separação entre os avanços científicos e tecnológicos e a reflexão ética o fizeram propor novas dimensões para a responsabilidade.

Por sua vez, G-R faz críticas à primeira lei da Termodinâmica ao não fazer distinção entre energia utilizável e energia não utilizável e por não excluir "a possibilidade de que uma quantidade de trabalho possa se transformar em calor [...] (e a de) que esse calor seja reconvertido na quantidade inicial de trabalho" (G-R, 20012, p. 81). G-R manifesta que esta lei, por si só, considera que um processo aconteça em um sentido ou em outro, retornando ao seu estado inicial sem que perdas irreversíveis existam. Essa observância para a primeira lei da termodinâmica se faz no bojo de uma visão mecanicista, não fazendo parte de processos reais onde os processos econômicos estão presentes.

Um olhar mais próximo dos fenômenos reais está presente na segunda lei da termodinâmica, onde as formas de energia transformadas gradativamente em calor, aumentam a entropia, levando ao aumento da energia não utilizável. Para a obtenção deste fluxo de energia, deve-se ter uma energia utilizável proveniente do estoque de minerais que, ao serem utilizados como combustíveis, se degradam em energia não utilizável, ou seja, "a matéria também está submetida a uma dissipação irrevogável" (G-R, p.82). Assim, energia e matéria se degradam. G-R chama a atenção para a degradação que o planeta sofre, de forma cada vez mais acelerada, pelos avanços da Ciência e da Tecnologia e para a manutenção de um 'padrão' de vida humano.

Ambos os estudiosos têm a preocupação primeira com a preservação do planeta e da espécie humana, e apresentam elementos que contribuem para a abordagem das ciências e da tecnologia num processo que foge ao puramente técnico e expositivo, mas que envolve o pensar a realidade econômica e ética exigida para a construção de vias sustentáveis, como indica o sociólogo Edgar Morin. O espaço desses possíveis encontros é o espaço educacional, um espaço de formação onde apreender as realidades, reconhecer e conhecer os problemas a fim de buscar e participar democraticamente das soluções, requer a apreensão de um conhecimento que é pertinente. (MORIN, 2011)

O conhecimento pertinente não é posto disciplinarmente, separado, desunido, compartimentado. Ele está intimamente relacionado com a formação de um pensamento complexo que visa justamente 
superar a dispersão e a desunião dos conhecimentos. Esse pensamento complexo, dialogicamente, ao mesmo tempo separa e religa: o ser humano da natureza e do cosmo, as culturas científica e humanística, o local e o global. (MORIN, 2015)

A separação das ciências em disciplinas hiperespecializadas, fechadas em si, a disjunção entre a humanidade e as ciências, o reducionismo que restringe o complexo ao simples e a falsa racionalidade são obstáculos presentes no sistema de ensino, conduzindo à atrofia da disposição mental natural de apreender o que está tecido junto. Para a formação do conhecimento pertinente, Morin baseia-se em quatro princípios: o contexto, o global, o multidimensional e o complexo.

O contexto é um referencial no qual as informações ou dados são situados e adquirem sentido. 0 global "é o conjunto das diversas partes ligadas a ele (contexto) de modo inter-retroativo ou organizacional" (MORIN, 2011, p. 34). O pensamento global insere em si uma concepção de sistema, de um todo organizado, onde "por meio da organização [...] o todo se constitui em algo mais do que a mera soma das partes" (Ibidem, 2015, p. 109). Ou seja, "o todo tem qualidades ou propriedades que não são encontradas nas partes, se [...] isoladas [...] certas qualidades ou propriedades das partes podem ser inibidas pelas restrições provenientes do todo" (Ibidem, 2011, p. 35). Nessa relação entre o todo e as partes, uma parte não pode ser isolada do todo, nem as partes umas das outras, revelando o princípio multidimensional.

Um exemplo, o ser humano (o todo) é ao mesmo tempo biológico, psíquico, social, afetivo e racional. A dimensão biológica pode ser estudada separadamente, mas o conhecimento pertinente necessita religá-lo ao todo assim como analisar e sintetizar a relação desta dimensão com as demais (psíquica, social, afetiva e racional). (MORIN, 2011)

Por fim, quando elementos diferentes constituem um todo e são inseparáveis, e existir uma relação interdependente, interativa e inter-retroativa entre o objeto de conhecimento e seu contexto, entre as partes e o todo, entre o todo e as partes e entre as partes entre si, tem-se a complexidade, temse aquilo que foi tecido junto. Os estudos de $\mathrm{H}$. Jonas e G-R propiciam a construção do conhecimento pertinente, não separando o ser humano entre o técnico e o humano, a ciência e a filosofia. Ao contrário, busca integrá-lo a um contexto maior do qual faz parte, o planeta Terra, e interligá-lo a outros seres pelos quais é responsável.

\section{ALGUMAS CONSIDERAÇÕES}

Os benefícios da ciência e da tecnologia são inegáveis. Por exemplo, a prevenção e o tratamento de doenças contribuem para o aumento da expectativa de vida; o desenvolvimento de infraestrutura e saneamento básico melhoram a qualidade de vida da população nas cidades; a possibilidade de atravessar oceanos em poucas horas ou de uma comunicação "quase" instantânea refletem o processo global que estamos vivendo. No entanto, isso tem vários custos: os vários problemas ambientais, o desemprego e a concentração de poder sobre os meios de produção, o controle de informação, entre outros tantos. O fato é que derivados do suporte que a ciência e a tecnologia deram aos processos econômicos, tais custos são globais, e acometem a todos.

Nosso estudo buscou tratar de tais aspectos da ciência e da tecnologia confrontando-os com as leis da Termodinâmica, para extrapolar a visão conteudista, puramente conceitual e tecnicista, de forma a reconhecê-las como a lei que trata da vida. G-R (2012) nos presenteia com reflexões muito atuais e urgentes acerca do necessário decrescimento econômico e pontua, como o cerne do problema 
ecológico a contradição da ideia de alcance de um 'desenvolvimento sustentável', de forma que a exigência de desenvolvimento se relaciona necessariamente com a expansão econômica de produção e de consumo, tal expansão provoca processos irreversíveis de degradação do mundo físico.

Desta forma, o estudo buscou iluminar para uma dimensão diferente e complementar sobre o estudo da Termodinâmica, cuja importância ultrapassa os aspectos técnicos e o usufruir das benesses tecnológicas, envolve também uma reflexão sobre o estar no mundo, as interferências do ser humano no mundo e o produto dessa relação. Ou seja, envolve, como defende Morin, a construção do conhecimento pertinente, nos instrumentalizando para mudar uma visão reducionista da Ciência ao discutir a finitude do planeta.

Contribuindo com este pensamento, com relação à luta que a humanidade trava contra o meio ambiente e contra si mesma, G-R faz um chamado para os universitários: seu dever "é contribuir para atenuar esse combate e não enganar os outros com ideias que escapam ao poder da ciência dos homens." (G-R, 2012, p. 156). E conclama, "o mundo tem a maior necessidade de uma nova ética" (Ibidem, p. 156). Nova ética ensaiada por Hans Jonas, ao construir o princípio responsabilidade para a civilização tecnológica, que suscita o cuidado e zelo para com a Biosfera, para com os seres humanos e os seres da natureza, para aqueles que estão e aqueles que podem vir a ser.

Por tudo isso, a reflexão apresentada neste estudo torna-se uma base para a construção do conhecimento pertinente, sendo um texto que se abre para possibilidades de análise e discussão tanto entre professores em momento de formação quanto entre professores e estudantes, dirigindo-nos especialmente aos formadores de profissionais das engenharias e áreas afins, trazendo luz sobre como perceber a Ciência no cotidiano, na percepção da finitude do planeta, na interdisciplinaridade entre a termodinâmica e a ecologia, o meio ambiente e a ética.

\section{REFERÊNCIAS}

BATTESTIN, Cláudia. GHIGGI, Gomercindo. O princípio responsabilidade de Hans Jonas: um princípio ético para os novos tempos. Thaumazein, Santa Maria, ano III, n.06, p. 69-85, out. 2010.

GEORGESCU-ROEGEN, Nicholas. O decrescimento: entropia, ecologia, economia. São Paulo: editora SENAC, 2012.

JONAS, Hans. O princípio responsabilidade: ensaio de uma ética para a civilização tecnológica. Rio de Janeiro: Contraponto: Ed. PUC-Rio, 2006.

KÖCHE, José Carlos. Fundamentos de metodologia científica: teoria da ciência e iniciação científica. Petrópolis, RJ: Vozes, 2011.

MORIN, Edgar. Os sete saberes necessários à educação do futuro. 2.ed.rev. São Paulo: Cortez; Brasília, DF: UNESCO, 2011.

MORIN, Edgar. Ensinar a viver: manifesto para mudar a Educação. Porto Alegre: Meridional, 2015.

PRODANOV, Cleber Cristiano; ERNANI, Cesar de Freitas. Metodologia do trabalho científico: métodos e técnicas da pesquisa e do trabalho acadêmico. 2ed. Novo Hamburgo: Feevale, 2013.

Submissão: 07/03/2021 